\title{
BMJ Open The influence of hazardous drinking on psychological functioning, stress and sleep during and after treatment in patients with mental health problems: a secondary analysis of a randomised controlled intervention study
}

\author{
Catharina Strid, ${ }^{1}$ Claes Andersson, ${ }^{2}$ Agneta Öjehagen ${ }^{3}$
}

To cite: Strid C, Andersson C, Öjehagen $A$. The influence of hazardous drinking on psychological functioning, stress and sleep during and after treatment in patients with mental health problems: a secondary analysis of a randomised controlled intervention study. BMJ Open 2018;8:e019128. doi:10.1136/ bmjopen-2017-019128

- Prepublication history for this paper is available online. To view these files, please visit the journal online (http://dx.doi org/10.1136/bmjopen-2017019128).

Received 13 September 2017 Revised 22 December 2017 Accepted 3 January 2018
Check for updates

${ }^{1}$ Department of Psychology, Lund University, Lund, Sweden ${ }^{2}$ Department of Criminology, Malmö University, Malmö, Sweden

${ }^{3}$ Department of Clinical Sciences, Psychiatry, Lund University, Lund, Sweden

Correspondence to Dr Catharina Strid; catharina.strid@psy.lu.se

\section{ABSTRACT}

Objectives Hazardous drinking could negatively affect health and lead to alcohol use disorders, but it is unclear how hazardous drinking affects treatment outcomes of depression and anxiety and stressrelated mental health problems. The aim of this study was to examine whether hazardous drinking, measured by Alcohol Use Disorders Identification Test-Consumption (AUDIT-C), influences the outcomes of repeated assessments of psychological functioning (Outcome Questionnaire-45), stress (Perceived Stress Scale) and sleep (Karolinska Sleep Questionnaire), during and after treatment in patients with mental ill health.

Methods The study was conducted within REGASSA, a randomised controlled trial aimed at comparing Internet-based cognitive-behaviour therapy and physical exercise with treatment as usual on primary care patients with mental ill health. The study involved 871 participants who completed the AUDIT at baseline and who were assessed repeatedly during and after treatment on psychological functioning, stress and sleep by interactive voice response, a computerised, automated telephone technology.

Results At baseline, hazardous drinkers were more depressed and had lower scores on psychological functioning than non-hazardous drinkers, while there were no differences on stress and sleep. During the follow-ups, hazardous drinking negatively influenced perceived stress, that is, hazardous drinkers seemed to have less treatment effect on stress, and the results remained after controlling for depression. There were no differences during the follow-ups regarding psychological functioning and sleep.

Conclusions Hazardous drinking negatively influenced perceived stress. The findings of the study emphasise the importance of screening for alcohol habits in mental ill-health patients, since risky drinking may affect the outcomes of treatment.

Trial registration number DRKS00008745; Post-results.
Strengths and limitations of this study

- This is a secondary analysis of randomised controlled trial (RCT) data and not a prospectively designed RCT, which was a limitation.

- However, the large sample of primary care patients was a strength.

- Another strength was the repeated assessments collected by automated technology, which was a convenient way of monitoring a large sample of participants

- The high attrition in the repeated assessments was a limitation, although the analysis model compensating for the attrition was a strength and the proportion of hazardous drinkers remained almost the same.

- The Alcohol Use Disorders Identification TestConsumption cut-off scores have not been validated in a population of mental health problems, which was a limitation.

\section{INTRODUCTION}

Hazardous or risky alcohol consumption is common in patients seeking primary care, but is often not adequately examined at the medical visit, ${ }^{12}$ and only some of the patients with risky consumption are advised to reduce their alcohol use. ${ }^{3}$ Hazardous drinking, including both the number of drinks consumed weekly and on a single occasion, 'binge drinking', is considered an alcohol drinking pattern that could lead to negative effects on health and to development of alcohol use disorders. ${ }^{45}$ Screening for alcohol use is a recommended intervention for patients in routine care, and patients reporting a pattern of hazardous drinking should be given advice on how to change this pattern and offered brief interventions. 
Patients with alcohol use disorder or dependence should be referred for treatment. ${ }^{6-8}$

Several studies have shown higher prevalence rates for hazardous drinking in patients with common mental health problems compared with the general population. ${ }^{69-11}$ Eberhard and colleagues ${ }^{10}$ found a prevalence of $21 \%$ in a population of psychiatric outpatients, and Nehlin and colleagues showed a proportion of $19 \%,{ }^{10}$ which was higher than that in the Swedish general population at the time $(15 \%)$. However, only a few studies have examined whether concomitant hazardous drinking affects treatment outcome of mental health problems. In an extensive review by Sullivan and colleagues, ${ }^{12}$ it could not be established whether hazardous drinking or alcohol use disorders influenced recovery from or relapse in depression, although the review only involved one study examining risk drinking. In that study, hazardous drinking did not affect recovery from depression. ${ }^{12}$ Gajecki and colleagues ${ }^{13}$ examined whether problematic substance use affected an Internet-based cognitivebehaviour therapy (ICBT) for depression and anxiety disorders, and found no differences in effect between hazardous and non-hazardous drinkers on depression, but hazardous drinkers showed less treatment effect for panic disorder. ${ }^{13}$ In another study on treatment of anxiety, alcohol use severity had no impact on treatment effect, although baseline hazardous alcohol use was associated with more anxiety and depression symptoms at long-term follow-up. ${ }^{14}$ Haynes and colleagues ${ }^{5}$ found little evidence that hazardous drinking is a risk factor in non-recovery from common mental disorders, but binge drinking may be a potential risk. ${ }^{5}$ Consequently, few studies have addressed the impact of hazardous alcohol use on treatment effects, and the findings are inconsistent, which justifies further research.

This study is a secondary analysis performed within the framework of REGASSA, a multicentre randomised controlled trial (RCT) conducted in primary care on patients with mild-to-moderate depression, anxiety and stress-related mental health problems. The objectives of REGASSA were to study the effects of ICBT and physical exercise (PE) compared with treatment as usual (TAU) on work ability and sick leave as primary outcome measures, and depression as secondary outcome. Other secondary outcome measures used were repeated assessments of psychological functioning, perceived stress and sleep. Data were collected by an automated telephone technique, interactive voice response (IVR), which enabled frequent follow-ups during and after treatment. In a previous analysis of REGASSA using these secondary outcomes, we found that ICBT and PE were more effective than TAU on psychological functioning and sleep, no differences were found on perceived stress and all three treatment groups improved. ${ }^{15}$

In this study, we wanted to explore whether hazardous alcohol use could predict the outcomes of sleep, psychological functioning and stress, factors that may be influenced by hazardous alcohol consumption. To the best of our knowledge, the relationship between hazardous drinking and the secondary variables of REGASSA has previously only been studied with less frequent follow-ups, or has not been studied at all.

Stress is known to be linked with sleeping problems and mood disorders. ${ }^{16-18}$ In a previous primary care study, high levels of stress were commonly reported in association with symptoms of anxiety and depression, ${ }^{19}$ and high levels of perceived stress have been shown to be associated with less antidepressant treatment effect. ${ }^{20}$

In an epidemiological study of more than 30000 individuals, Dawson $e t a l^{21}$ found that stress resulted in increased quantities of alcohol consumption on specific drinking occasions, rather than more frequent drinking. Sher et al reported no clear results of whether alcohol reduces perceived stress, and concluded that stress is likely to be influenced by both individual and situational factors. ${ }^{22}$

Vinson and colleagues conducted a study in primary care on sleep and alcohol consumption and found no associations between hazardous drinking and sleeping problems. ${ }^{23}$ To the best of our knowledge, how hazardous drinking may affect change in psychological functioning (Outcome Questionnairet-45, OQ-45) has not yet been studied.

At baseline, patients in REGASSA completed the Alcohol Use Disorders Identification Test (AUDIT), which was developed for early detection of individuals with hazardous or harmful alcohol drinking. ${ }^{24}$ A previous cross-sectional study of REGASSA showed that the total AUDIT score, the scores of AUDIT-C and the proportions of hazardous drinkers (22\%) were higher among REGASSA patients compared with the general population $(15 \%){ }^{25}$

This study aimed to examine whether hazardous drinking at baseline predicts the outcomes of repeated assessments of psychological functioning, stress and sleep collected by IVR during and after treatment in REGASSA.

\section{METHODS}

\section{Study design}

Study design, participants and measurements are presented in more detail in an earlier study, ${ }^{15}$ and only a brief description is given here. REGASSA was carried out in primary care in six healthcare regions in Sweden between 2011 and 2014. After giving written informed consent, patients were randomised to one of three treatment alternatives, ICBT, PE and TAU, for a 12-week intervention. At baseline, participants completed a battery of questionnaires, including measures of depression (Montgomery Åsberg Depression Rating Scale, MADRS) and alcohol use (AUDIT), and follow-ups were conducted 3 and 12 months after baseline. Secondary outcomes of psychological functioning, stress and sleep were continually collected by IVR during and after treatment.

IVR is an automated telephone system programmed to administer various questionnaires and to follow a large population over time. At baseline, the patients in REGASSA registered their personal mobile number and answered the 55 questions included in IVR using 
Table 1 Baseline scores for non-hazardous drinkers and hazardous drinkers on sociodemographic data, depression (MADRS), psychological functioning (OQ-45), stress (PSS) and sleep (KSQ), the allocation in each three treatment condition, ICBT, PE and TAU, and the numbers (\%) still in follow-up

\begin{tabular}{lll}
\hline Variables & $\begin{array}{l}\text { Non- } \\
\text { hazardous } \\
\mathbf{n}=\mathbf{7 4 9}\end{array}$ & $\begin{array}{l}\text { Hazardous } \\
\mathbf{n}=\mathbf{1 2 2}\end{array}$ \\
\hline $\begin{array}{l}\text { Age, Mean }( \pm S D) \\
\text { Gender, \% }\end{array}$ & $43.4(12.0)$ & $40.7(13.1)$ \\
Male & 25 & 35
\end{tabular}

Education, \%

$\begin{array}{lll}\text { Low } & 4 & 5 \\ \text { Medium } & 35 & 38 \\ \text { High } & 61 & 57\end{array}$

Employment, \%

\begin{tabular}{lll}
\hline Employed/study & 81 & 82 \\
\hline Pension & 4 & 3 \\
\hline Unemployed & 10 & 3 \\
\hline Sick leave & 5 & 12
\end{tabular}

Civil state, \%

\begin{tabular}{lll} 
Living alone & 37 & 43 \\
\hline MADRS, Mean $( \pm S D)$ & $21.3(7.1)$ & $23.0(6.9)$ \\
\hline Depression level, \% & & \\
No depression & 9 & 4 \\
\hline Mild depression & 33 & 27 \\
Moderate depression & 55 & 65 \\
\hline Severe depression & 3 & 4 \\
\hline OQ-45, Mean $( \pm S D)$ & $83.7(19.6)$ & $89.0(17.9)$ \\
\hline PSS, Mean $( \pm S D)$ & $8.9(2.5)$ & $9.3(2.5)$ \\
KSQ, Mean $( \pm S D)$ & $14.7(4.4)$ & $14.6(4.4)$ \\
Allocation, \% & & \\
ICBT & 35 & 29 \\
PE & 33 & 38 \\
TAU & 32 & 34
\end{tabular}

Numbers still in follow-up, \%

\begin{tabular}{lll}
3 months & 55 & 50 \\
6 months & 48 & 39 \\
9 months & 48 & 41 \\
12 months & 26 & 24 \\
\hline
\end{tabular}

ICBT, Internet-based cognitive-behaviour therapy;

KSQ, Karolinska Sleep Questionnaire; OQ-45, Outcome Questionnaire-45; PE, physical exercise; PSS, Perceived Stress Scale; MADRS, Montgomery Åsberg Depression Rating Scale; TAU, treatment as usual.

touch-tone technology. The automated system then called the patients on six measurement occasions: two during treatment, one at the end of treatment and three after treatment until 12 months after baseline. The attrition in IVR showed varying but decreasing levels over the 12-month study period (table 1 ). The proportion of responders at 3-month follow-up was 54\%, at 6 month $47 \%$, at 9 month $47 \%$ and at the final 12-month follow-up the proportion of responders had fallen to $25 \%$. The proportion of hazardous drinkers remained almost constant, $15 \%$ at 3-month follow-up, $13 \%$ at 6 months, $14 \%$ at 9 months and $15 \%$ at 12 -month follow-up. The number of responders is presented in figure 1.

\section{Participants}

Participants were primary care patients with light-tomoderate depression, anxiety and stress-related mental ill health. The inclusion criteria were $\geqq 10$ points on the Patient Health Questionnaire-9, a short depression scale, and Swedish language skills due to the ICBT programme, being only delivered in Swedish. REGASSA included 945 patients, of which 879 completed the IVR baseline assessments and, of these 879 patients, 871 also completed AUDIT at baseline. Patients with a primary substance use disorder were excluded. The CONSORT diagram (figure 1) shows the flow of the participants and the number of responders at each follow-up for hazardous and non-hazardous drinkers.

\section{Measures at baseline AUDIT}

AUDIT is a 10-item scale for measuring alcohol consumption and alcohol-related problems. The test is validated in primary care and has shown acceptable psychometric properties. ${ }^{24}$ AUDIT is in two parts: items 1-3 measuring alcohol consumption (AUDIT-C) and items 4-10 measuring alcohol problems (dependency and harm combined). In this study, we only used the abbreviated consumption subscale AUDIT-C, since the three questions in OQ-45 on negative consequences of drinking behaviour would otherwise interfere with questions 4-10 in AUDIT. The items in AUDIT-C are (1) How often do you drink alcohol? (2) How many glasses do you drink on a typical day when you drink alcohol? (3) How often do you have six or more drinks on one occasion? The scores range from 0 to 4 , and maximum negative score is 12. AUDIT-C has shown high specificity and sensitivity in screening for risky alcohol habits. ${ }^{26} 27$ The cut-off score for hazardous drinking in this study was set to $\geq 5$ for women and $\geq 6$ for men in accordance with Swedish guidelines. ${ }^{28}$ These cut-offs are higher than in previous studies where the cut-off scores have been set to $\geq 3-4$ for women and $\geq 4-5$ for men, but it is recommended that cut-off scores are determined empirically in different cultures, since drinking frequency varies largely between countries. ${ }^{6112627}$

When studying the question of binge drinking separately, the cut-off was set to at least on a monthly basis for both women and men.

\section{MADRS}

In earlier REGASSA studies, MADRS was used as an outcome measure for depression but, in this study, it was 


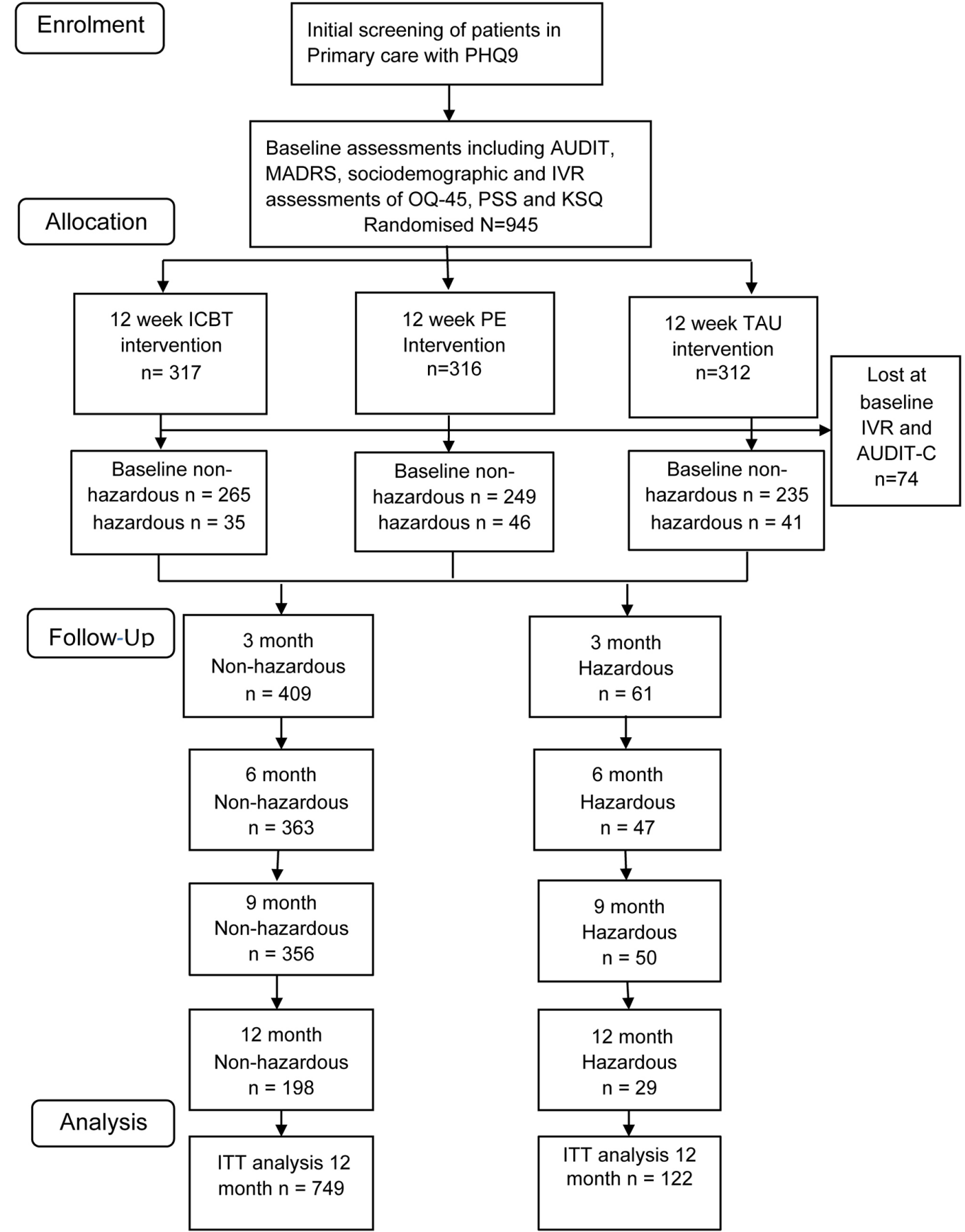

Figure 1 The CONSORT diagram shows the participants' flow through the study. AUDIT-C, Alcohol Use Disorders Identification Test-Consumption; ICBT, Internet-based cognitive-behaviour therapy; ITT, intention to treat; IVR, interactive voice response; KSQ, Karolinska Sleep Questionnaire; OQ-45, Outcome Questionnaire-45; PE, physical exercise; PHQ-9, Patient Health Questionnaire-9; PSS, Perceived Stress Scale; MADRS, Montgomery Åsberg Depression Rating Scale; TAU, treatment as usual.

used as a baseline measurement and only for controlling results obtained with AUDIT-C. MADRS is a commonly used measure for depression that has shown good psychometric properties. It consists of 10 items with six response alternatives. ${ }^{29}$

\section{Gender}

We analysed whether there were any gender differences in terms of hazardous drinking and its influence on the outcome measures of psychological functioning, sleep and stress.

\section{Outcome measurements in IVR}

Outcome Questionnaire-45

The repeated assessments of psychological functioning were measured by OQ-45. OQ-45 was developed by Lambert and colleagues to measure psychotherapy effects. ${ }^{30}$ It consists of 45 questions with a score range 
of $0-180$, where 180 is the maximum negative score. OQ-45 captures the patient's psychological functioning through questions about symptoms, interpersonal problems and social role function. Both the original and the Swedish version of OQ-45 have shown good psychometric properties. $^{30-32}$

\section{Perceived Stress Scale}

Stress was repeatedly assessed by the Perceived Stress Scale (PSS), originally a 10-item scale measuring how the patient copes with stress. In this study, we used a shortened four-item version of this scale that has proved suitable for telephone assessments. ${ }^{33}$ The scores range from 0 to 4 , and the maximum total negative score is 16 .

\section{Karolinska Sleep Questionnaire}

A short version of the Karolinska Sleep Questionnaire (KSQ) assessed the sleep outcome. The questionnaire comprises four items capturing sleep quality, with scores ranging from 1 to 6 , and the maximum negative score was 24. KSQ has shown good validity, reliability and sensitivity in various studies,. ${ }^{34}$

\section{Statistics}

Differences between hazardous drinkers and non-hazardous drinkers were calculated on continuous baseline measurements using independent samples t-tests, and differences in proportions of hazardous drinkers in discrete variables were examined with $\mathrm{X}^{2}$ tests. Differences in attrition between non-hazardous and hazardous drinkers were calculated with Fisher's exact test. To examine how alcohol consumption (AUDIT-C) at baseline affected the course and outcome for psychological functioning, stress and sleep, we conducted three separate analyses with linear mixed models with a first-order autoregressive, heterogeneous rho covariance structure. Mixed models include all measures that are available at each assessment, and were therefore considered suitable for this study. We assumed that missing observations were unrelated to the observed value, that is, missing at random. Each model included six follow-ups called assessments 1, 2, 3, 4, 5 and 6; the assigned treatment groups ICBT, PE and TAU; gender; and two baseline measures, that is, hazardous drinking (AUDIT-C) and the baseline scores of one of the three outcome measures (OQ- 45 , PSS, KSQ). All variables were modelled as fixed effects. The outcome measure baseline scores were used as continuous covariate, and the control variable hazardous drinking (AUDIT-C) and gender as categorical covariates. AUDIT-C was a dichotomous variable, where 0 was defined as non-hazardous drinking and 1 hazardous drinking. MADRS was used as a continuous covariate for controlling for depression if AUDIT-C showed significant influence on the outcome measures. Assessment data were nominal, that is, each measurement occasion was separate and time was not a continuous linear regressor in the model. The analyses began with a full model with interaction effects of AUDIT-C $\times$ Treatment group $\times$ Assessment and was simplified to main group effects if no significant interaction effects were found. Before the results were analysed, the residuals were examined and showed a normal distribution. A test for robustness showed similar results as the mixed model analysis. All statistics were performed in the SPSS V.22.0 for Windows.

\section{RESULTS}

The average age of patients was 43 years, and $62 \%$ had a high level of education. Most of the patients were working and only $5 \%$ were on sick leave. In table 1 , different descriptions of baseline measurements for hazardous drinkers and non-hazardous drinkers and attrition during the follow-ups are presented.

The proportion of hazardous drinkers at baseline measured by AUDIT-C was 14\%, with a significantly higher proportion in men (18\%) compared with women (12\%), $\chi^{2}=5.23 \mathrm{P}=0.022$. The proportions of binge drinkers measured by item 3 in AUDIT-C was 13\%, and the overlap between hazardous and binge drinkers was high; 90 out of the 122 hazardous drinkers were also binge drinkers, and 90 of the 110 binge drinkers were hazardous drinkers, so our analysis focused solely on the summarised score in AUDIT-C as a measure of hazardous drinking. The baseline average depression score (MADRS) showed moderate depressive problems, and hazardous drinkers were more depressed $t(853)=-2.31, \mathrm{P}=0.021$ and had lower psychological functioning $(\mathrm{OQ}-45) t(871)=-2.85$, $\mathrm{P}=0.004$ than non-hazardous drinkers. There were no baseline differences between the treatment alternatives, perceived stress, sleep or age, education level, civil state and employment. The Fisher's exact test showed no differences in attrition between non-hazardous and hazardous drinkers at any follow-up and there were no differences between the treatment alternatives.

The results of the linear mixed models showed that hazardous alcohol consumption at baseline predicted the outcome for perceived stress (PSS). The patients with hazardous drinking had a higher average score on PSS throughout the assessments, which might indicate less treatment effect for perceived stress compared with non-hazardous drinkers. To test whether this effect could be due to depression, since hazardous drinkers were more depressed than non-hazardous, we carried out a new analysis with MADRS and AUDIT-C as baseline covariates, and both MADRS $\mathrm{P}=0.003$ and AUDIT-C $\mathrm{P}=0.022$ were significant, that is, the effects of hazardous drinking remained. In the full model, we included interaction effects between hazardous alcohol consumption and treatment alternatives and hazardous alcohol consumption and the IVR assessments, but no significant interaction effects were found. The model was reduced to main effects of group, including a control for differences at baseline between hazardous and non-hazardous drinkers; the results are presented in table 2.

The main effect of group occurred after baseline, that is, during and after treatment, so hazardous drinkers 
Table 2 The influence of alcohol consumption on repeated assessments of perceived stress as the main effect of group presented in average change scores

\begin{tabular}{|c|c|c|c|c|}
\hline Variables & $\begin{array}{l}\text { Average } \\
\text { change }\end{array}$ & df & $\mathbf{t}$ & $95 \% \mathrm{Cl}$ \\
\hline $\begin{array}{l}\text { Assessment } \\
1\end{array}$ & 0 & & & \\
\hline $\begin{array}{l}\text { Assessment } \\
2 \dagger\end{array}$ & -0.43 & 725.65 & $-4.39^{\star \star \star}$ & $(-0.63$ to -0.24$)$ \\
\hline $\begin{array}{l}\text { Assessment } \\
\text { 3† }\end{array}$ & -1.02 & 707.27 & $-9.00^{\star \star \star}$ & $(-1.25$ to -0.80$)$ \\
\hline $\begin{array}{l}\text { Assessment } \\
4 \dagger\end{array}$ & -1.06 & 621.12 & $-8.52^{\star \star \star}$ & $(-1.30$ to -0.81$)$ \\
\hline $\begin{array}{l}\text { Assessment } \\
5 \dagger\end{array}$ & -1.28 & 601.23 & $-9.78^{\star \star \star}$ & $(-1.53$ to 1.02$)$ \\
\hline $\begin{array}{l}\text { Assessment } \\
6 \dagger\end{array}$ & -1.49 & 319.69 & 1.78 & $(-1.79$ to 1.19$)$ \\
\hline Genderł & 0.32 & 642.18 & & $(-0.03$ to 0.66$)$ \\
\hline AUDIT-C§ & 0.61 & 668.58 & $2.65^{\star \star \star}$ & (0.16 to 1.06$)$ \\
\hline
\end{tabular}

Assessment 1 is set to zero because it is a redundant. $\dagger A$ negative score means a reduction from assessment 1 . $\ddagger A$ positive score means that the average score of assessments 1-6 shows a larger reduction from assessment 1 in women as compared with men.

$\S A$ positive score means that the average score of assessments 1-6 shows a larger reduction from assessment 1 in non-hazardous as compared with hazardous drinkers.

${ }^{*} \mathrm{P}<0.05,{ }^{* *} \mathrm{P}<0.01,{ }^{* * *} \mathrm{P}<0.001$.

AUDIT-C, Alcohol Use Disorders Identification Test-Consumption.

probably had less treatment effect even if no differences in how hazardous drinking predicted stress were found between the treatment alternatives. The average changes on PSS over the assessments for patients with and without hazardous drinking are presented in figure 2. The differences in stress between hazardous drinkers and non-hazardous drinkers were higher at the follow-ups conducted after the end of treatment, but these figures should be treated with some caution because of the large attrition, even if there were no differences in attrition between the two groups.

The results of the linear mixed models on psychological functioning (OQ-45) and sleep (KSQ) were not significantly influenced by the level of hazardous alcohol consumption at baseline, although there was a tendency $(\mathrm{P}=0.064)$ for higher average scores on OQ-45 for hazardous drinkers compared with non-hazardous drinkers (tables 3 and 4). Since the main effect of group was not significant on OQ-45 and KSQ, interaction effects between hazardous drinking and treatment group or hazardous drinking and assessments were not examined.

\section{DISCUSSION}

The aim of this study was to examine whether hazardous alcohol consumption predicts the outcome for psychological functioning, perceived stress and sleep, over a 12 -month assessment period. The results showed that hazardous drinking predicted stress, but not psychological functioning and sleep. Patients with hazardous drinking had a higher level of stress during the follow-ups compared with non-hazardous drinkers, but not at baseline, and these results remained after controlling for depression. In a previous study in REGASSA, ${ }^{15}$ we reported that the treatment had positive effect on perceived stress, and all treatment groups showed improvements. This study adds that the improvement was negatively influenced by hazardous drinking, that is, hazardous drinkers improved less than non-hazardous drinkers irrespective of treatment alternative.

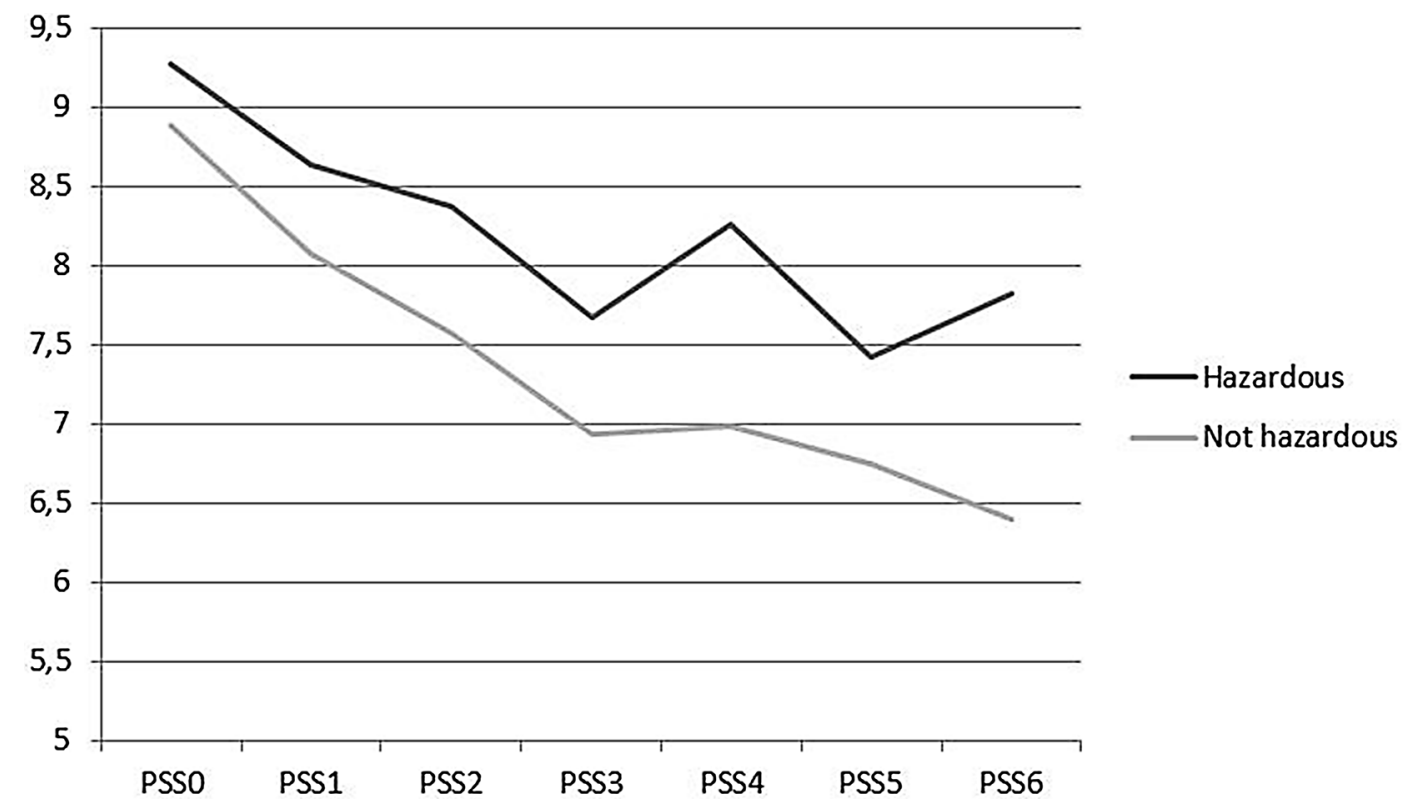

Figure 2 The graph shows the course of stress during and after treatment for patients with and without hazardous drinking at baseline. 
Table 3 The influence of alcohol consumption on repeated assessments of Outcome Questionnaire-45 as the main effect of group presented in average change scores

\begin{tabular}{|c|c|c|c|c|}
\hline Variables & $\begin{array}{l}\text { Average } \\
\text { change }\end{array}$ & df & $\mathbf{t}$ & $95 \% \mathrm{Cl}$ \\
\hline $\begin{array}{l}\text { Assessment } \\
1\end{array}$ & 0 & 0 & 0 & \\
\hline $\begin{array}{l}\text { Assessment } \\
2 \dagger\end{array}$ & -4.00 & 724.13 & $-7.19^{\star \star \star}$ & (-5.09 to 2.91$)$ \\
\hline $\begin{array}{l}\text { Assessment } \\
3 \dagger\end{array}$ & -8.50 & 694.62 & $-11.52^{\star \star \star}$ & $(-9.95$ to 7.05$)$ \\
\hline $\begin{array}{l}\text { Assessment } \\
4 \dagger\end{array}$ & -9.87 & 579.86 & $-11.15^{\star \star \star}$ & $(-11.61$ to 8.13$)$ \\
\hline $\begin{array}{l}\text { Assessment } \\
5 \dagger\end{array}$ & -10.07 & 497.79 & $-10.28^{\star \star \star}$ & $(-12.00$ to 8.15$)$ \\
\hline $\begin{array}{l}\text { Assessment } \\
6 \dagger\end{array}$ & -11.83 & 291.60 & $-10.05^{\star \star \star}$ & $(-14.14$ to 9.51$)$ \\
\hline Genderł & 2.62 & 605.08 & 1.79 & $(-0.25$ to 5.48$)$ \\
\hline AUDIT-C§ & 3.50 & 627.39 & 1.86 & $(-0.20$ to 7.21$)$ \\
\hline
\end{tabular}

Assessment 1 is set to zero because it is a redundant. †A negative score means a reduction from assessment 1 . $\ddagger A$ positive score means that the average score of assessments 1-6 shows a larger reduction from assessment 1 in women as compared with men.

$\S A$ positive score means that the average score of assessments 1-6 shows a larger reduction from assessment 1 in non-hazardous drinkers as compared with hazardous.

${ }^{*} \mathrm{P}<0.05,{ }^{* *} \mathrm{P}<0.01,{ }^{* * *} \mathrm{P}<0.001$,

AUDIT-C, Alcohol Use Disorder Identification Test-Consumption.

Dawson and colleagues, who separated binge drinking from other consumption measures, found that stress was associated with binge drinking and not with frequency of drinking. ${ }^{21}$ In our study, binge drinking was a part of hazardous drinking in the summarised measure of AUDIT-C, which might explain our results that hazardous drinking was associated with higher levels of stress. Hazardous drinkers seemed to get less treatment effects on stress, which is not in line with the assumption that alcohol could reduce stress. Although it is uncertain whether alcohol reduces stress, its effect on stress seems to depend on several factors. ${ }^{22}$ The focus in this study was on hazardous alcohol consumption, which may not reduce stress. The influence of alcohol use on stress seems unclear, and further investigations are required.

The finding that hazardous drinking did not affect sleep quality is in line with an earlier study conducted in primary care, ${ }^{23}$ but contradicts other findings where risky alcohol users have reported lower sleep quality. ${ }^{35}$

When comparing the baseline scores of OQ-45 in our sample of depressed patients with samples of patients with alcohol use disorders, the patients in our sample showed lower psychological functioning, and this applied for both hazardous and non-hazardous drinkers. ${ }^{31} 36$ Hazardous drinkers had a significantly higher score on OQ-45 at baseline but, during follow-ups, these differences were no longer significant, although a tendency towards higher
Table 4 The influence of alcohol consumption on repeated assessments of sleep as the main effect of group presented in average change scores

\begin{tabular}{lllll}
\hline Variables & $\begin{array}{l}\text { Average } \\
\text { change }\end{array}$ & $\mathbf{d f}$ & $\mathbf{t}$ & $\mathbf{9 5 \%} \mathbf{~ C l}$ \\
\hline $\begin{array}{l}\text { Assessment } \\
1\end{array}$ & 0 & & & \\
\hline $\begin{array}{l}\text { Assessment } \\
2 \dagger\end{array}$ & -0.44 & 710.76 & $-3.49^{\star \star *}$ & $(-0.69$ to -0.19$)$ \\
$\begin{array}{l}\text { Assessment } \\
\text { 3† }\end{array}$ & -1.02 & 759.76 & -6.47 & $(-1.33$ to -0.71$)$ \\
$\begin{array}{l}\text { Assessment } \\
4 \dagger\end{array}$ & -1.05 & 649.15 & -5.78 & $(-1.41$ to -0.70$)$ \\
$\begin{array}{l}\text { Assessment } \\
5 \dagger\end{array}$ & -1.02 & 632.79 & -5.76 & $(-1.36$ to -0.67$)$ \\
\hline $\begin{array}{l}\text { Assessment } \\
6 \dagger\end{array}$ & -1.31 & 338.53 & -5.88 & $(-1.74$ to -0.87$)$ \\
\hline $\begin{array}{l}\text { Gender } \\
\text { AUDIT-C§ }\end{array}$ & 0.14 & 635.91 & 0.53 & $(-0.37$ to 0.65$)$ \\
\hline
\end{tabular}

Assessment 1 is set to zero because it is a redundant.

†A negative score means a reduction from assessment 1 .

$\ddagger A$ positive score means that the average score of assessments

1-6 shows a larger reduction from assessment 1 in women as compared with men.

$\S A$ positive score means that the average score of assessments 1-6 shows a larger reduction from assessment 1 in non-hazardous as compared with hazardous drinkers.

${ }^{*} \mathrm{P}<0.05,{ }^{* *} \mathrm{P}<0.01,{ }^{* * *} \mathrm{P}<0.001$.

AUDIT-C, Alcohol Use Disorder Identification Test-Consumption.

scores remained. In summary, results of our analyses were unclear about the way hazardous drinking affects psychological functioning, and more research is needed.

Several studies have concluded that alcohol use patterns should be screened in healthcare, and the AUDIT-C has been recommended as a suitable screening test. ${ }^{6726}$ A common barrier for addressing alcohol habits in healthcare is lack of time, so a short screening tool such as the AUDIT-C could be a facilitator, ${ }^{17}$ as well as automated technology. The patients in REGASSA turned out to have higher proportions of hazardous drinking and alcohol problems than the general population, ${ }^{25}$ which emphasises the need to examine the alcohol patterns and increase the amount of advice on alcohol consumption given to patients with mental ill health. Systematic screening for alcohol use in primary care has been shown to increase the detection of hazardous drinkers, and facilitate brief interventions. ${ }^{7}$ The results in our study confirm the importance of screening for drinking habits in primary care to identify risky consumption that may have an impact on treatment effects on perceived stress for patients with common mental health problems.

\section{Strengths and limitations}

The large sample of mental ill-health patients in primary care is an advantage and strengthens the 
results. However, the present design, a secondary analysis of RCT data, examining the prediction of alcohol consumption on psychological functioning, stress and sleep, is not powered to fully answer the question, which is a limitation. The chosen cut-off scores of AUDIT-C, which are recommended by the Swedish national guidelines, have not been validated in a population of patients with mental health problems, which is a limitation. The repeated assessments in IVR is a strength that enabled us to make reliable comparisons and to follow the patients throughout the study. The analysis model is a strength compensating for the high attrition in IVR, which is otherwise a limitation. Conclusions about differences on stress between hazardous drinkers and non-hazardous in later follow-ups should be drawn with caution due to attrition, although the attrition was not higher among hazardous drinkers during the follow-ups.

\section{CONCLUSION}

This study showed that hazardous drinkers were more depressed and had lower psychological functioning at baseline and higher level of stress during and after treatment. These results add to previous studies on the importance of screening for alcohol consumption in mental ill-health patients seeking primary care, since hazardous drinking may influence some treatment effects. Further research is needed on how hazardous drinking affects different treatment outcomes in patients with common mental health problems.

Acknowledgements We thank Peter Höglund in Skåne regional council for statistical advice and Lars-Gunnar Lundh at the Department of Psychology, Lund University, for valuable comments on the manuscript.

Contributors CS was involved in the data collecting process, made major contributions to the data analysis and was a major contributor in writing the manuscript. CA was involved in the study design and the data collecting process, made contributions to the data analysis and writing process. $\mathrm{AO}$ was vice director for the REGASSA study and was involved in the study design, made contributions to the data analysis and the writing process. All authors read and approved the final manuscript.

Funding The REGASSA study was funded by Stockholm, Kronoberg, Västmanland and Blekinge county councils, Skåne and Västra Götaland regional councils in Sweden, and REHSAM through Vårdal Foundation.

Disclaimer The funding sources had no part in study design, data analysis or writing the manuscript.

Competing interests None declared.

Patient consent Obtained.

Ethics approval The REGASSA study was approved by the regional ethical review board at Karolinska Institutet in Stockholm (Dnr 2010/1779-31/4) and retrospectively registered in German clinical trials DRKS00008745. Before allocation, a written informed consent was obtained from each patient.

Provenance and peer review Not commissioned; externally peer reviewed.

Data sharing statement The datasets generated and/or analysed during the current study are not publicly available due to that there is no permission granted for this from the ethical review board, but are available from the corresponding author on reasonable request.

Open Access This is an Open Access article distributed in accordance with the Creative Commons Attribution Non Commercial (CC BY-NC 4.0) license, which permits others to distribute, remix, adapt, build upon this work non-commercially, and license their derivative works on different terms, provided the original work is properly cited and the use is non-commercial. See: http://creativecommons.org/ licenses/by-nc/4.0/

(C) Article author(s) (or their employer(s) unless otherwise stated in the text of the article) 2018. All rights reserved. No commercial use is permitted unless otherwise expressly granted.

\section{REFERENCES}

1. Holmqvist M, Bendtsen P, Spak F, et al. Asking patients about their drinking. A national survey among primary health care physicians and nurses in Sweden. Addict Behav 2008;33:301-14.

2. Nordström A, Bodlund O. Every third patient in primary care suffers from depression, anxiety or alcohol problems. Nord J Psychiatry 2008;62:250-5.

3. Satre DD, Leibowitz AS, Mertens JR, et al. Advising depression patients to reduce alcohol and drug use: factors associated with provider intervention in outpatient psychiatry. Am J Addict 2014;23:570-5.

4. Dawson DA, Li TK, Grant BF. A prospective study of risk drinking: at risk for what? Drug Alcohol Depend 2008;95:62-72.

5. Haynes JC, Farrell M, Singleton N, et al. Alcohol consumption as a risk factor for non-recovery from common mental disorder: results from the longitudinal follow-up of the National Psychiatric Morbidity Survey. Psychol Med 2008;38:451-5.

6. Nehlin C, Fredriksson A, Jansson L. Brief alcohol screening in a clinical psychiatric population: special attention needed. Drug Alcohol Rev 2012;31:538-43.

7. Reinholdz H, Fornazar R, Bendtsen P, et al. Comparison of systematic versus targeted screening for detection of risky drinking in primary care. Alcohol Alcohol 2013;48:172-9.

8. Rehm J, Anderson P, Manthey J, et al. Alcohol use disorders in primary health care: what do we know and where do we go? Alcohol Alcohol 2016;51:422-7.

9. Bellos S, Skapinakis P, Rai D, et al. Cross-cultural patterns of the association between varying levels of alcohol consumption and the common mental disorders of depression and anxiety: secondary analysis of the WHO Collaborative Study on Psychological Problems in General Health Care. Drug Alcohol Depend 2013;133:825-31.

10. Eberhard S, Nordström G, Höglund P, et al. Secondary prevention of hazardous alcohol consumption in psychiatric out-patients: a randomised controlled study. Soc Psychiatry Psychiatr Epidemiol 2009;44:1013-21.

11. Kaarne T, Aalto M, Kuokkanen M, et al. AUDIT-C, AUDIT-3 and AUDIT-QF in screening risky drinking among Finnish occupational health-care patients. Drug Alcohol Rev 2010;29:563-7.

12. Sullivan LE, Fiellin DA, O'Connor PG. The prevalence and impact of alcohol problems in major depression: a systematic review. Am J Med 2005;118:330-41.

13. Gajecki M, Berman AH, Sinadinovic K, et al. Effects of baseline problematic alcohol and drug use on internet-based cognitive behavioral therapy outcomes for depression, panic disorder and social anxiety disorder. PLOS One 2014;9:e104615:1-10.

14. Wolitzky-Taylor K, Brown LA, Roy-Byrne P, et al. The impact of alcohol use severity on anxiety treatment outcomes in a large effectiveness trial in primary care. J Anxiety Disord 2015;30:88-93.

15. Strid C, Andersson C, Forsell $\mathrm{Y}$, et al. Internet-based cognitive behaviour therapy and physical exercise - Effects studied by automated telephone assessments in mental ill-health patients; a randomized controlled trial. Br J Clin Psychol 2016;55:414-28.

16. Akerstedt T, Knutsson A, Westerholm P, et al. Sleep disturbances, work stress and work hours: a cross-sectional study. J Psychosom Res 2002;53:741-8.

17. Tkachenko O, Olson EA, Weber M, et al. Sleep difficulties are associated with increased symptoms of psychopathology. Exp Brain Res 2014;232:1567-74.

18. Leggett A, Burgard S, Zivin K. The impact of sleep disturbance on the association between stressful life events and depressive symptoms. J Gerontol B Psychol Sci Soc Sci 2016;71:118-28.

19. Wiegner L, Hange D, Björkelund C, et al. Prevalence of perceived stress and associations to symptoms of exhaustion, depression and anxiety in a working age population seeking primary care - an observational study. BMC Fam Pract 2015;16:1-8.

20. Kim JM, Kim SW, Stewart R, et al. Stressful events, stress perception and treatment outcomes in patients with depressive disorders: the CRESCEND study. J Affect Disord 2011;133:528-36.

21. Dawson DA, Grant BF, Ruan WJ. The association between stress and drinking: modifying effects of gender and vulnerability. Alcohol Alcohol 2005;40:453-60. 
22. Sher KJ, Bartholow BD, Peuser K, et al. Stress-response-dampening effects of alcohol: attention as a mediator and moderator. J Abnorm Psychol 2007;116:362-77

23. Vinson DC, Manning BK, Galliher JM, et al. Alcohol and sleep problems in primary care patients: a report from the AAFP National Research Network. Ann Fam Med 2010;8:484-92.

24. Babor TF, Higgins-Biddle JC, Saunders JB, et al. AUDIT The Alcohol Use Disorders Identification Test: Guidelines for use in Primary Care: World Health Organization, Department of Mental Health and Substance Dependence, 2001. http://www.who.int/substance abuse/publications/audit/en/ (accessed 12 Mar 2017).

25. Åhlin J, Hallgren $\mathrm{M}$, Öjehagen $\mathrm{A}$, et al. Adults with mild to moderate depression exhibit more alcohol related problems compared to the general adult population: a cross sectional study. BMC Public Health 2015;15:542.

26. Bradley KA, DeBenedetti AF, Volk RJ, et al. AUDIT-C as a brief screen for alcohol misuse in primary care. Alcohol Clin Exp Res 2007;31:1208-17.

27. Lundin A, Hallgren M, Balliu N, et al. The use of alcohol use disorders identification test (AUDIT) in detecting alcohol use disorder and risk drinking in the general population: validation of AUDIT using schedules for clinical assessment in neuropsychiatry. Alcohol Clin Exp Res 2015;39:158-65.

28. Regeringskansliet. Uppföljning av regeringens alkohol-, narkotika-, dopnings- och tobaksstrategi 3 - Förslag på indikatorer avseende de prioriterade målen i strategin, bilaga 2;2015 Government Offices. The governments' follow-up of alcohol, drug, doping and tobacco strategy 3 - Proposed indicators for the priority objectives of the strategy, appendix. 2015;2.

29. Montgomery SA, Asberg M. A new depression scale designed to be sensitive to change. Br J Psychiatry 1979;134:382-9.

30. Lambert MJ, Burlingame GM, Umphress V, et al. The reliability and validity of the outcome questionnaire. Clin Psychol Psychother 1996;3:249-58.

31. Wennberg P, Philips B, de Jong K. The Swedish version of the outcome questionnaire (OQ-45): reliability and factor structure in a substance abuse sample. Psychol Psychother 2010;83:325-9.

32. Strid C, Lundh L-G, Andersson C, et al. Psychometric properties of the Swedish version of the Outcome Questionnaire-45 as administered by automated technique in a large sample of mental ill-health patients in Primary Health Care. The European Journal of Psychiatry 2014;28:242-51.

33. Cohen S, Kamarck T, Mermelstein R. A global measure of perceived stress. J Health Soc Behav 1983;24:385-96.

34. Nordin M, Åkerstedt T, Nordin S. Psychometric evaluation and normative data for the Karolinska Sleep Questionnaire. Sleep Biol Rhythms 2013;11:216-26.

35. Ogeil RP, Phillips JG, Rajaratnam SM, et al. Risky drug use and effects on sleep quality and daytime sleepiness. Hum Psychopharmacol 2015;30:356-63.

36. Crits-Christoph P, Markell HM, Gallop R, et al. Predicting outcome of substance abuse treatment in a feedback study: Can recovery curves be improved upon? Psychother Res 2015;25:694-704. 